\title{
Sedimentary Petrology Characteristics and Their Implications for Provenance of Flowerpot Basin Jurassic System in Yanqiing County, Beijing
}

\author{
Yaxuan Yuan, Hongliang Wang* \\ School of Energy Resources, China University of Geosciences, Beijing, China \\ Email: yuan_yaxuan@163.com, whliang@cugb.edu.cn
}

Received 4 May 2016; accepted 11 June 2016; published 14 June 2016

Copyright (C) 2016 by authors and Scientific Research Publishing Inc.

This work is licensed under the Creative Commons Attribution International License (CC BY). http://creativecommons.org/licenses/by/4.0/

(c) (i) Open Access

\section{Abstract}

The characteristics of sedimentary petrology are significant in determining geological provenance. By using field outcrop observation and indoor identification of thin sections, the characteristics of Jurassic system Tuchengzi Formation clastic rocks exposed in the Beijing Yanqing "flowerpot" basin, which include rock types, clastic composition and cement type, etc. have been analyzed systematically to identify the provenance direction and tectonic setting and nature of the provenance. Research shows that the sedimentary rocks in this area belong to analluvial fan and braided river sedimentary rock system and include mainly conglomerates, lithic sandstone, and feldspathic lithic sandstone. The main compositions of the conglomerate are dolomite and limestone. Nearly $50 \%$ to $70 \%$ of the sandstones are mainly polycrystalline quartz; $10 \%$ to $15 \%$ are feldspar; and $40 \%$ to $55 \%$ are composed of debris from mainly magmatic and metamorphic rocks. A Dickinson triangular diagram indicates that the provenance type in this area is recycled orogny evolving from clastic recycled orogeny such as a collisional orogenic belt to a transitional recycled orogeny. On the basis of the geographic position and tectonic setting, three types of provenance can be identified in the Jurassic system Tuchengzi Formation. The far source provenances are Archean erathem basement metamorphic rocks in the northern basin and granite or adamellite that intruded rocks of the Late Jurassic epoch of the Yanshanian period in the northeast. The nearby provenance is the Mesoproterozoic erathem Changchengian system and Jixianianian system dolomite in both the east and west.

\section{Keywords}

Tuchengzi Formation, Sandstone Components, Petrologic Characteristics, Provenance Analysis,

\footnotetext{
${ }^{*}$ Corresponding author.
}

How to cite this paper: Yuan, Y.X. and Wang, H.L. (2016) Sedimentary Petrology Characteristics and Their Implications for Provenance of Flowerpot Basin Jurassic System in Yanqing County, Beijing. Journal of Geoscience and Environment Protection, 4, 69-79. http://dx.doi.org/10.4236/gep.2016.46006 


\section{Dickinson Triangular Diagram}

\section{Introduction}

Provenance analysis is an effective method for discriminating the types of the sedimentary mother rock, restoring the sedimentary environment, and determining the geographic location of the mother rock district. In addition, this method is used to indicate the provenance direction and controlling factors of a sedimentary system. Studies of sedimentary petrology characteristics are significant for determining the mother rock and the provenance. Owing to its mineral composition, a sandstone skeleton is sensitive to natural processes and the tectonic environment of provenance. Thus, a method that uses sandstone composition to determine the tectonic nature of the provenance area is widely used in basin analysis and in discussions of basin type and evolution [1]. In the past, many studies have been conducted on basin provenance. Among them, Dickinson [2] put forward and established a diagram of the relationship between the compositions of sandstone skeletons and their tectonic environments according to the different characteristics of plate tectonic units. The Dickinson triangular diagram includes three primary and seven secondary provenances [2]. For the next 10 years, these models have undergone little improvement; Ingersoll et al. [3] developed the Gazzi-Dickinson method of microscopic statistics. This method, which is used to discuss basin type and evolution, is more accurate in basin analysis than the former method and is used widely. Moreover, it successfully identifies many tectonic settings of provenance areas.

Previous studies in the Flowerpot Basin have focused mainly on the structural properties and sedimentary system. For example, Zhang et al. [4] reported that the Flowerpot basin underwent large tectonic subsidence twice. They determined that during the early stage of the Flowerpot basin, two major lake-floodingcycles and many volcanic events occurred during the period of flooding development. Guo et al. [5] reported that the sedimentary system of this area belongs to abraided river deposit system in which the main types of microfacies include channel, pond, channel-bar, overflow, and overbank deposits consisting of crevasse splays and crevasse channels. However, research is lacking for the characteristics of Jurassic system Tuchengzi Formation (J3h) sedimentary rocks and their provenance direction. Therefore, research of the petrologic characteristics in the study area, including the clastic components and filler content characteristics, and their comparison with those of the surrounding strata is of great significance for understating the basin-fill sequence. Furthermore, revealing the provenance of the basin sediments and their tectonic setting also helps to clarify the relationship between the provenance and sedimentary area. Such research also helps to determine the path and distance of sediment transport and the provenance.

\section{Geology Setting}

Yanqing National Geopark of Silica Woods is located along the Bai River in northeast Yanqing County approximately30 km from the city of Yanqing and about $100 \mathrm{~km}$ from Beijing to the southeast. It is the only national geological park in North China that includes typical, rare, and precious petrified woods as the main landscape [6] [7]. The study area is the central region of Xin Shan Zi village, Qian Jia Dian town, and Yanqing County, Beijing, commonly known as the Flowerpot Basin (Figure 1). This basin is located in the eastern region of the Pot-Sihai folded area of the Yanshan fold belt. The main exposed stratum is part of the Upper Jurassic Tuchengzi Formation that formed 156 - 139 Ma. This formation, known as the Houcheng Formation before 1990, is situated near the Houcheng area of Chicheng County, Hebei Province. Therefore, the Houcheng Formation in Hebei Province and the Tuchengzi Formation in western Liaoning Province include the same strata [8]. The strata over the Tiaojishan Formation are in unconformable contact with the underlying strata.

\subsection{Tectonic Conditions}

After the Lvliang movement at about 1800 Ma, which formed the North China craton at the end of the Paleoproterozoic era, the Yanshan area was relatively stable from the Mesoproterozoic to the late Paleozoic era with no major tectonic deformation. Since the Mesozoic, collisions and interactions between the North China blocks and adjacent plots have caused strong tectonic deformation and intracontinental orogeny in the northern region of the North China craton. Owing to N-S movement of the Siberian plate and the North China plate, a N-S 


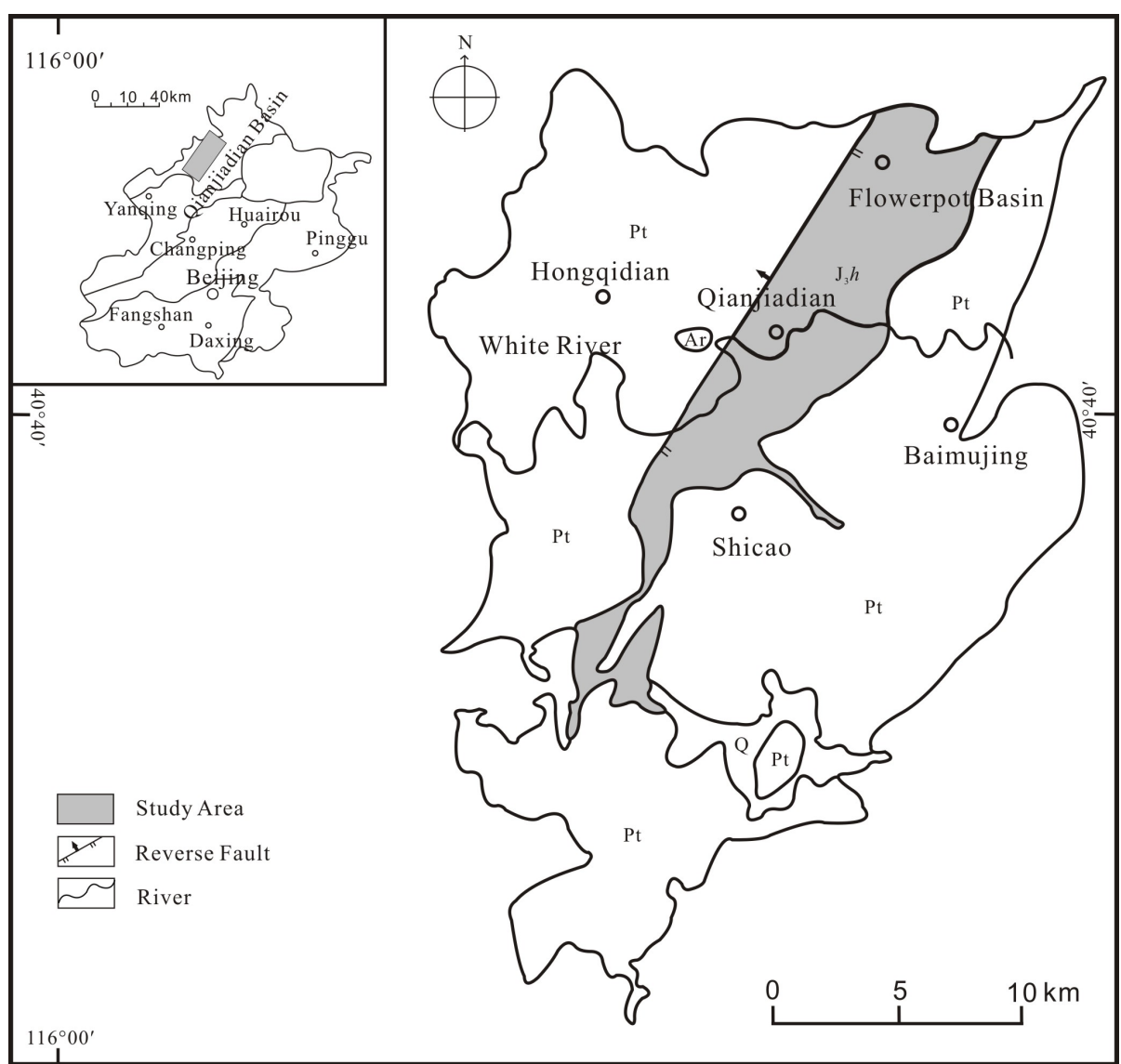

Figure 1. Location map of Yanqing National Geopark of Silica Woods, based on the regional geology record of Beijing (1991).

compressive stress field formed in the middle-late Jurassic that caused crustal thickening and produced the volcanic rock of the Tiaojishan Formation in an intracontinental compression environment [9].

The Tuchengzi and Tiaojishan formations have the same tectonic background, and both include volcanic rock from deep-seated crust. Volcanic eruption occurred under the conditions of lithospheric stretching and in association with the activities of deep faults [10]. Numerous studies have been conducted on the formation time, spatial distribution, and structural evolution of the Tuchengzi Formation. Zhao [11] determined the that Tuchengzi Formation formed in the late middle Yanshanian and that its emergence and distribution is closely related tothrust faulting, nappe structures, and fault uplift. Shao [12] reported that the Tuchengzi Formation formed in a decentralized multiple fault basin that was controlled by the stretching conditions. Liu [13] reported that in the late Jurassic, the extensional environment caused by mantle upwelling resulted in a fault depression in the region. Essentially, the sedimentary process of the clastic rock of the Tuchengzi Formation was unstable. In addition, the Tuchengzi Formation was in the second stage of Yanshan movement. In the early stage, a large number of neutral volcanoes erupted to form numerous volcanic-sedimentary fault basins. After deposition, deformation formed a fold in the NE direction that has deflection of about $20^{\circ}$ compared with the axis of the underlying E-NE direction fold that formed during the early Yanshan movement. Tectonic compression with thrust nappe characteristics resulted in an inversion of the early extensive basin [12]. These events formed the basic tectonic framework of the region.

\subsection{Stratum Conditions}

In the study area, the exposed stratum is part of the Mesozoic Jurassic Tuchengzi Formation, which consists mainly of reseda shale, silty shale, light-green-dark-purple breccia tuff, tuffaceous grit, tuffaceous sandstone, siltstone, polymictic conglomerate with small amounts of trachyandensite, andesite, and volcanic breccia com- 
plex components. The petrified wood was found in the reseda shale and silty shale [14]. Previous research has shown that the Tuchengzi Formation is lake-river deposit composed of coarse-grain alluvial fans and braided rivers in the lower part and lake-river deposits intercalated with volcanic rocks in the upper part [4].

\section{Methodology}

A geological field survey of the study area involved outcrop observation and laboratory investigation. According to the rock development situation in this area, observed 11 field outcrop and collected representative samples from 6 different locations. For the mineralogical study, 15 representative fresh samples of the sandstone and conglomerate were selected for thin-section petrography. The main job during the field exploration are: identify the sedimentary facies, determine the types of rocks preliminary, and observe rock's textural characteristics of the macro structure. They provided the information for indoor thin section identification. Then take the microscopic identification for 15 thin section by polarizing microscope, and statistic the clastic constituent content and interstitial materials content with point counting method. Then observed the microscopic structure of clastic particles. Finally the petrologic characteristics of sandstone and conglomerate of Tuchengzi Formation is systemically studied.

\section{Petrologic Characteristics}

\subsection{Rock Types}

The types of rock exposed in the research area include polymictic conglomerates, gritstone, medium sandstone, fine sandstone, and mudstone. The braided river sedimentary system, which is widely distributed, includes mainly medium-fine sandstone, gritstone, conglomerate at the bottom of the river detainment sedimentation, and a small amount of mudstone. Polymictic conglomerates are developed in the alluvial fan, particularly in the root fan and middle fan. Sandstone provides important evidence for evaluating the types of mother rock in the provenance area; thus, detailed and accurate quantitative analysis of the clastic composition of sandstone is important for analyzing the provenance area and determining the nature of a sedimentary basin. Therefore, on the basis of the sedimentary rock skeleton particle content and the Chinese petroleum and natural gas industry standard known as Thin Section Examination of Rock (SY/T5368-2000), 15 rock simples of the Jurassic Tuchengzi Formation in the Flowerpot Basin in Yanqing county were been classified and named. As shown in Figure 2, the triangle chart has three end members representing the percentage compositions of quartz and feldspar and the sum of lithoclasts, mica, and chlorite. On the basis of the relative amounts of the different end members, rock types can be determined in the studied area [15]. This study determined that the types of sandstone in the Flowerpot Basin are lithic sandstone and feldspar lithic sandstone.

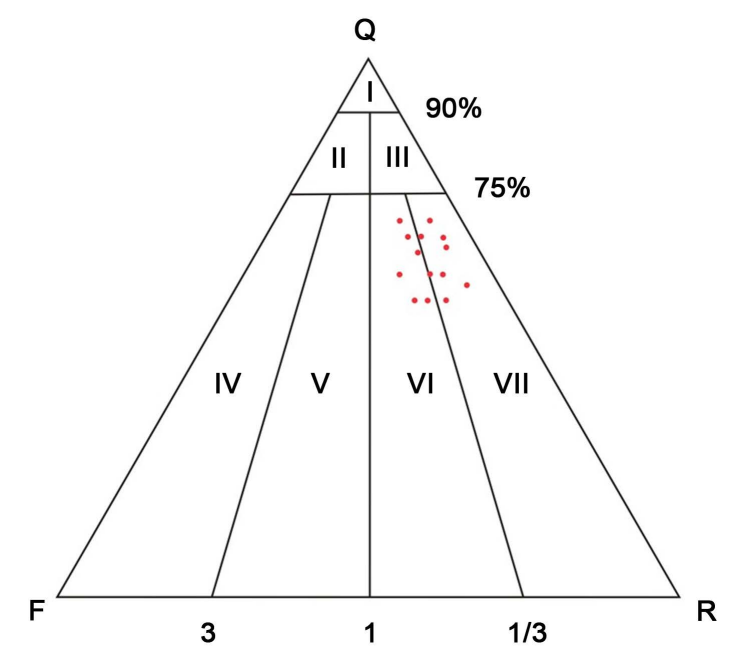

Figure 2. Triangular diagram for the classification of sandstones in the Tuchengzi Formation. I: quartz sandstone; II: feldspathic quartz sandstone; III: lithic quartz sandstone; IV: feldspar sandstone; V: lithic feldspar sandstone; VI: feldspar lithic sandstone; VII: lithic sandstone. 


\subsection{Characteristics of Sandstone Clastic Components}

Clastic components of sandstone such as quartz, feldspar, and lithoclasts are significant for determining the mother rock in the provenance area. Quartz is the most abundant mineral in sandstone and is relatively stable in the processes of weathering, transporting, and diagenesis. Thus, by studying the types and characteristics of quartz grains such as the extinction types of quartz, the contact properties of sub-particles in polycrystalline particles, the particle shape, and types of inclusions, its relationship with the mother rock can be determined. Feldspar is also a highly useful marker of mother rock; thus, the content of feldspar can be used as a standard in determining the provenance area distance. Because feldspar is relatively instable and the weathering and abrasion directly reflect transport conditions, many sedimentary basins have a feldspar abundance. The physical and chemical properties of this feldspar are also significant in determining its genesis. For example, quantitative analysis of the chemical components, bicrystals, annules, and structural state of feldspar is the main method in current usage for determining the mother rock [16]-[18]. Lithoclasts serve as an important index in determining the mother rock because the provenance is often directly from the mother rock. Lithoclasts corrode quickly; however, those deposited in close proximity to the mother rock can be preserved. Therefore, lithoclasts serve as the most direct evidence in evaluating the types of mother rock.

\subsubsection{Quartz \& Chert}

The quartz in the samples occurs mainly in two different types of psephicity: angular and sub-rounded. The rounding condition can indicate more than one provenance, and the distances between provenances differ significantly. In addition, the particles are not of uniform size, and the separation is mediocre. Usually, the smaller particles that are considered to be the result of weathering, denudation, and recrushing when the mother rocks are transported have higher roundness. The earlier formative quartz was formed by recrushing; the boundary between the particles is not clear. According to microscopic observation, single-crystal quartz accounts for about $20 \%$ to $30 \%$, and polycrystalline quartz accounts for about $30 \%$ to $40 \%$. Most of the polycrystalline quartz contains more than four sub-particles. $70 \%-80 \%$ of the quartz exhibits middle-high wavy extinction; a lower amount of quartz particles presents parallel extinction. Thus, the type of mother rock can be determined primarily as metamorphic rock. However, some particles exhibit obvious grain breakage; quartz surfaces commonly show groups of ruptures and microgrooves. Cement is visible in some places in fractures and without secondary enlargement. Large amounts of gas, liquid inclusions, and heavy mineral particles are present inside the quartz and exhibit smooth and clean surfaces (Figure 3(A)). The chert content, usually exhibiting aphanitic texture, is up to $8 \%$, (Figure $3(\mathrm{~B})$ ). These features indicate that magmatic rock, particularly volcanic rock and granite, is an additional type of mother rock.

\subsubsection{Feldspar}

The feldspar particle granularity is generally large and is often columnar or granulous. Both separation and rounding are not common; grains are often sub-rounded or sub-angular. Feldspar accounts for about $20 \%-30 \%$ in sandstone, $80 \%$ of which shows evidence of alteration. Plagioclase generally accounts for about $5 \%-8 \%$ with a maximum of $15 \%$. Sericitization on the plagioclase surfaces is strong; fresh particles are rare. K-feldspar is generally less and accounts for less than $5 \%$. Kaolinization on the K-feldspar surfaces is strong. Microcline alteration is generally light and is accompanied by mild clay mineralization (Figure 3(C) and Figure 3(D)). Furthermore, a few metasomatic wormlike structures formed by wormlike quartz aggregates in the graphic feldspar and plagioclase crystals are present.

\subsubsection{Lithoclasts}

The lithoclast content accounts for about $40 \%$ - 50\% in the sandstone, the main components of which are volcanic and metamorphic lithoclasts with a few sedimentary lithoclasts. Among them, the volcanic lithoclast content is highest, accounting for about $10 \%-20 \%$, and the particle size is about $1-2 \mathrm{~mm}$. These lithoclasts are composed mainly of granite, granodiorite, and tuff. Metamorphic lithoclasts account for about $15 \%-25 \%$ and are composed mainly of metaquartzite, mica schist, phylite, and silicolites such as flint stripes and quartz veins (Figures 3(E)-(H)). Mineral wavy extinction is common in these types of lithoclasts. Generally, the quartzite lithoclasts are composed of quartz grains with dentate boundaries; very few flat boundary grains are present. Schistose quartzite caused by flattening and stretching presents dentate granoblastic textures. Extremely small 

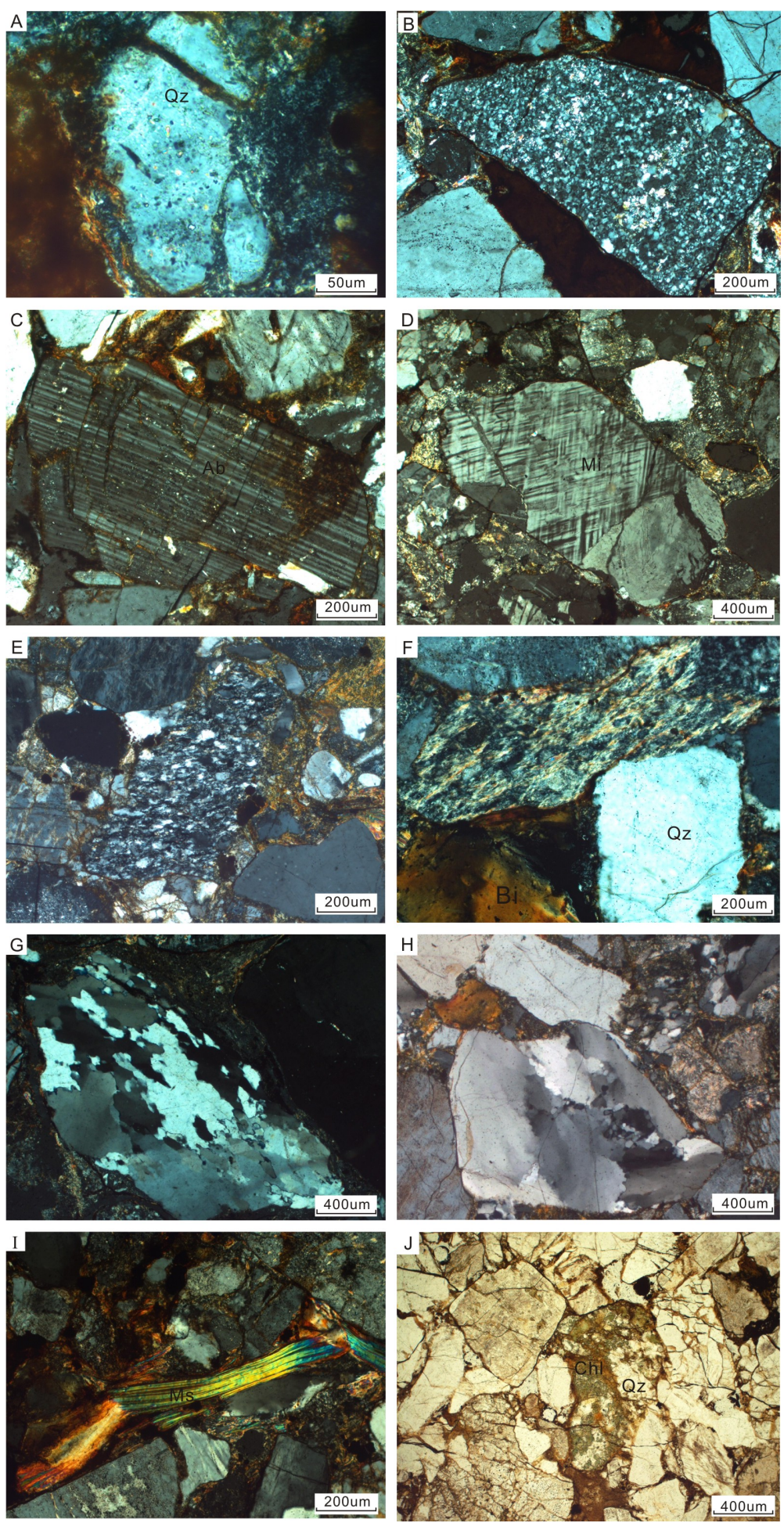

Figure 3. Sandstone petrologic characteristics of the Tuchengzi Formation in the Flowerpot Basin. (A) Quartz under perpendicular polarized light at $40 \times 10$; (B) Chert under perpendicular polarized light at $10 \times 10$; (C) Plagioclases under perpendicular polarized light at $10 \times 10$; (D) Microcline under perpendicular polarized light at $5 \times 10$; (E) Quartz schist lithoclast under perpendicular polarized light at $10 \times 10$; (F) Mica schist lithoclast under perpendicular polarized light at $10 \times 10$; $(\mathrm{G})$ Quartz vein under perpendicular polarized light at $5 \times 10$; $(\mathrm{H})$ Metamorphic quartzite rock debris under perpendicular polarized light at $5 \times 10$; (I) Muscovite under perpendicular polarized light at $5 \times 10$; (J) Chlorite film under plane-polarized light at $5 \times 10$. 
amounts of quartz and a few white mica and sericite grains are observable in the metamorphic quartzite lithoclasts and quartz sands. About $5 \%-10 \%$ of the sedimentary rock is cut by carbonate rocks and mudstone debris.

\subsubsection{Mica and Chlorite}

The content of mica in the sandstone components is only about $2 \%-3 \%$. Muscoviteis the main type and is present in schistose and thread textures with very bright level two-level three interference colors. Bending deflection or fracturing is present in the borders with lithoclasts. Schistose black mica, which has lower resistance to weathering than white mica, is less than $1 \%$ and is distributed among clastic particles. Chlorite, which is present in schistose texture or as aggregation among particles, is also very rare at about $1 \%-2 \%$; some wormlike textures are attached to the surfaces of quartz particles (Figure 3(J)).

\subsubsection{Interstitial Materials}

Interstitial materials include matrices and cements. In the medium-fine sandstone, matrices composed of clay and mica particles account for about $8 \%-10 \%$. These matrices are distributed in the intergranular pores and fractures and float in the forms of tie line contact or suspension. The cement content is about $2 \%-5 \%$, most of which is composed of iron, iron argillaceous, or calcite cementation. Iron argillaceous cementation is composed of mud impregnated by iron oxide. In coarse sandstones, the content of the matrix is about $5 \%-10 \%$, and the contact relationship among the particles is a line-bump contact. The cement accounting for about $5 \%-10 \%$ is composed of iron, mud, or a mixture of the two. Examination by using polarizing and fluorescence microscopes revealed that the cements contain a large amount of limonite and pyrite, which indicates a type of underwater reducing environment often present in multiphase superimposed braided river channel or interchannel deposition. The interstitial materials in the alluvial fan conglomerate developed in the Flowerpot Basin are mainly carbonate minerals including calcite, dolomite, and siderite. Furthermore, sandstone pores and micro-cracks are often filled by carbonate rocks, particularly calcite euhedral-subhedral grains dispersed in crystalline-granular textures.

\section{Provenance Area and Tectonic Setting Analysis}

\subsection{Source Type Evaluation}

Sandstone is the main type of terrigenous clastic rock, and its detrital materials originate mainly from the mechanical weathering of mother rock. Therefore, the detrital components of sandstone are significant in determining the provenance type [19] [20]. Two sets of provenance analysis diagrams of detrital composition, which were developed by Dickinson and Suczek [2] and Dickinson [3], were used to systematically analyze the contents of quartz, feldspar, and lithoclasts in the sandstone samples obtained from the Jurassic Tuchengzi Formation in the study area. Two triangle diagrams with three end members labeled as Q, F, L, and Qm, F, Lt, respectively, were used to determine the type of provenance (Figure 4).
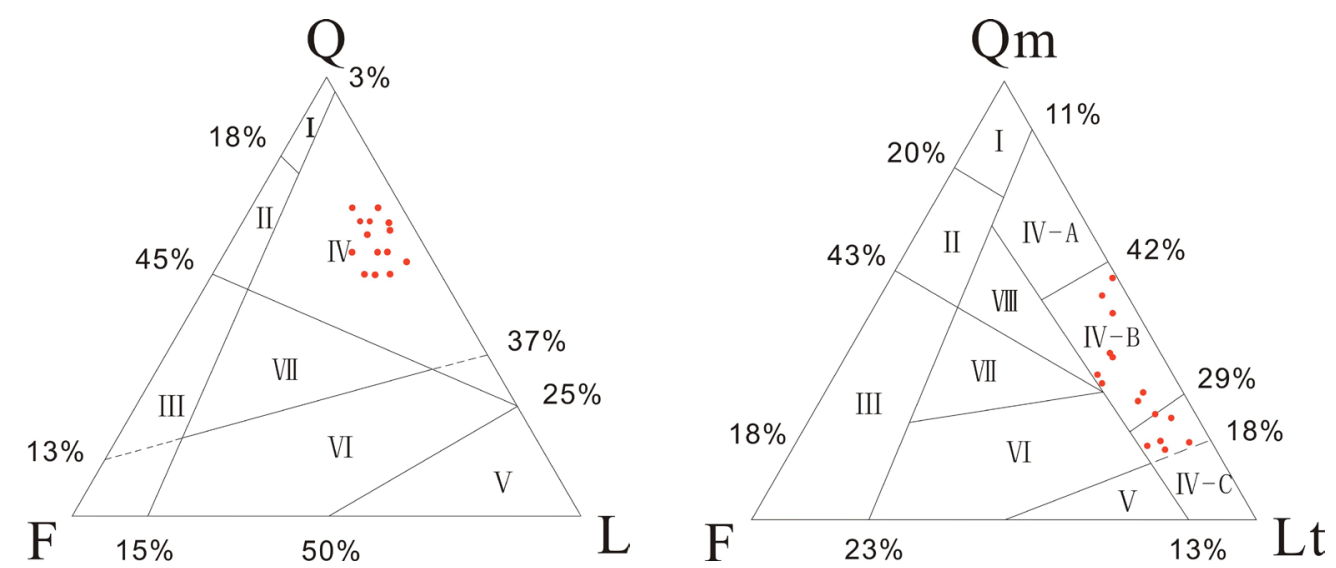

Figure 4. Dickinson Q-F-L, Qm-F-Lt triangular plots of sandstone clastic components of the Tuchengzi Formation. I: intracratonic block; II: transition continental block; III: uplifted basement; IV-A: quartziferous recycling orogeny; IV-B: transitional belt; IV-C: lithic recycling orogeny; V: uncut arc provenance; VI: transitional belt; VII: dissected arc provenance; VIII: mixing provenance; Q: total quartz; F: total feldspar; L: unstable lithic; Qm: monocrystalline quartz; Lt: total lithic. 
The discussion and analysis of the relationship between plate tectonics and the provenance of the Jurassic Tuchengzi Formation clastic rocks revealed that all projection points from the Q, F, L triangle diagram are located in the recycled orogeny belt provenance area. However, in the Qm, F, Lt triangle diagram, the projection points are located in transitional recycled orogeny and lithic recycled orogeny provenance areas [21]. According to the regional geological characteristics and the positions of the projection points, the samples originate from a landmass of recycled continental orogeny. Therefore, the provenance type in this basin is recycled orogeny, which reflects the processes of evolution from a clastic recycled orogeny such as a collisional orogenic belt to a transitional recycled orogeny.

\subsection{Provenance Analysis}

The results of the Dickinson triangular diagram have been previously used to determine the tectonic setting of provenance. Because the tectonic movement in the study area is highly complex, concrete analysis should be conducted for each specific question. The geographical position and mother rock type in the provenance area will be further discussed in accordance with the significant petrologic characteristics of sedimentary rock that indicate the provenance of the Tuchengzi Formation.

\subsubsection{Conglomerate Composition Analysis}

Two main types of conglomerate are present in the Tuchengzi Formation in the study area and are located respectively in a braided river sedimentary area and an alluvial fan development area. Previous studies have been conducted on the conglomerate of Tuchengzi Formation. The basal conglomerate has been shown to belong to the braided fluvial plain sedimentary system, and the Tuchengzi Formation developed in north rim of the basin overlaps Archeozoic basal metamorphic rocks [22]. Therefore, the sources of provenance include Archeozoic basal metamorphic rocks and metamorphic granite located in the north rim of the Flowerpot Basin. Another type of conglomerate is limited in distribution and is developed mainly in the direction of the short axis of the alluvial fan. This rock has developed mainly into multi-colored or red polymictic conglomerate with poor sorting and rounding, and the particles are arranged at high angles. The size of the conglomerate is complex with grains ranging from about $5 \mathrm{~cm}$ to $50 \mathrm{~cm}$; most are $15 \mathrm{~cm}$. Its miscellaneous support base is composed mainly of carbonate rocks such as dolomite and limestone (Figure 5). The clastic compositions in the carbonate rocks are mainly chert with dolomite from the middle-upper Proterozoic and a small amount of limestone representing fast and proximal sediment from the early Paleozoic. The paleocurrent direction is to the southeast [10], and a large amount of carbonate strata from the Paleozoic or Proterozoic is present on the west and east sides of the basin. Therefore, another provenance may be the dolomite from the Mesoproterozoic erathem Changchengian system or Jixian system in the northwest basin.

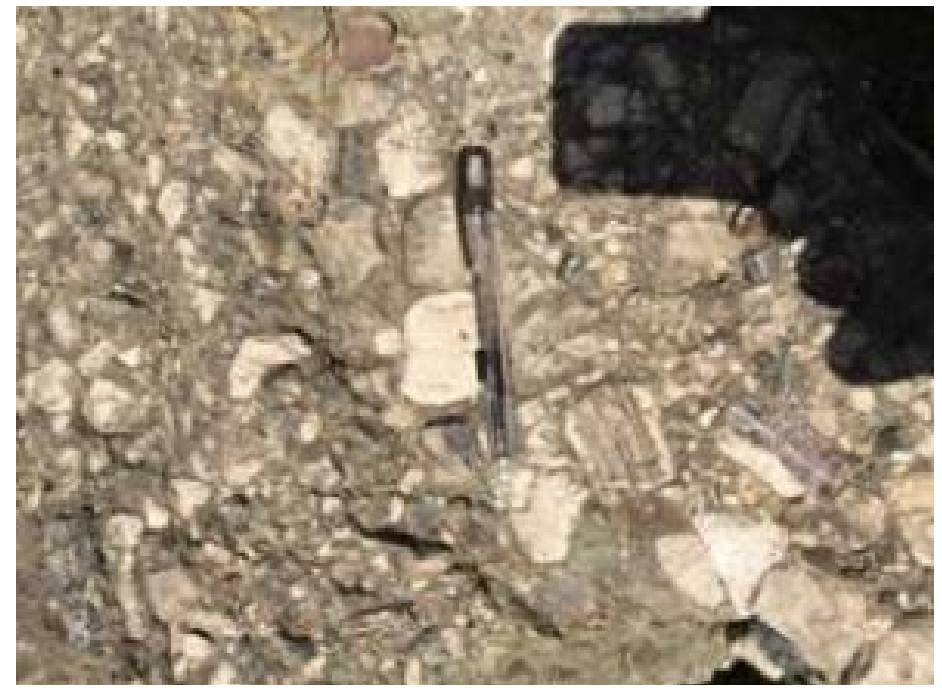

Figure 5. Petrologic features of conglomerate in the Flowerpot Basin. This reddish-brown conglomerate is situated in the root of an alluvial fan and is composed mainly of dolomite. 


\subsubsection{Feldspar Indicating Significance to Provenance}

Sediments from the provenance area undergo transport processes prior to deposition in which denudation plays an important role. The erosion process creates abundant amounts of easily weathered materials in the provenance that are carried by the current; the effect is less for weather-resistant materials [16]. Identification and analysis of rock slices revealed a low content of feldspar that shows obvious weathering and denudation on the surface. Plagioclase and K-feldspar shows everesericitization and kaolinization, respectively, which is the result of severe denudation during transportation owing to the weak weathering resistance offeldspar. The presence of these features prove that the mother rock in source area exposed on the earth's surface underwent denudation. The content of feldspar is generally related to differences in terrain elevation, erosion rate, and climate factors. The low content of feldspar generally indicates distant provenance. However, the content of lithoclastsis higher in the sample because of the reciprocal relationship of feldspar and lithoclasts.

\subsubsection{Lithic Information Indicating Significance to Provenance}

Lithic information is usually saved when rapid denudation occurs near the parent rock. Clastics provide a highthe lithic content in rock samples, which is favorable for determining the provenance of the mother rock. It is widely accepted that metamorphic and volcanic lithoclasts represent the provenance of the parent rock. The metamorphic rock lithoclasts in the study area include mainly granite gneiss, quartzite, and schist. Therefore, the mother rock of metamorphic rock lithoclastsis likely the metamorphic granite and basement metamorphic rock from the Archean in the northern basin. Volcanic activities were very active throughout the Jurassic period. In the Tuchengzi Formation, lacustrine facies sedimentary and volcanic event deposits are often associated with the Flowerpot Basin [4]. The lithoclast cycle in the Tuchengzi Formation reflects the processes of multiple exposure and denudation of the source areas covered by volcanic rocks [23]. In association with the Jurassic gabbro diorite group intrusion in Yanshanian, which developed in Archean metamorphic rocks in the northeastern basin, the volcanic rock lithoclasts are composed mainly of granite [24]. In addition, the types of rock also include acidic intrusive rocks having nearly the same components as the volcanic rock lithoclasts in the sandstone, such as granite, granodiorite, and adamellite. Therefore, the mother rocks of volcanic rock lithoclasts in this basin may be the granite from distant source provenance located in the northeastern basin. Moreover, sedimentary rock lithoclasts composed mostly of mudstone are abundant; however, they cannot represent the source of provenance because they are the product of sediments from the early river and floodplain that were washed and redeposited. In the development of the braided river, the plain sediments that formed previously were then broken into new syngenetic boulders, most of which developed the conglomerate.

\subsubsection{Determining Provenance}

The strata direction of the Jurassic Tuchengzi Formation is from NE-SW. These strata developed mainly from the braided river and river flood-lake; alluvial fans are present in the short axis. According to the above analysis, the major provenance is the braided river. In accordance with the Dickinson diagram, which shows the recycled orogeny provenance, the lower content of feldspar indicates a distant provenance. Moreover, the metamorphic rocks lithoclasts show specific provenance conditions. The primary provenance is Archeozoic basal metamorphic rock in the northern basin, and the secondary provenance is Mesoproterozoic dolomite of the Changcheng and Jixianian Wumishan Formation present in both sides of the basin (Figure 6).

\section{Conclusions}

The characteristic components of the Jurassic Tuchengzi Formation clastic rocks exposed in the Beijing Yanqing Flowerpot Basin were analyzed in this study. The main results are given in the following points:

1) The main rock types of Jurassic Tuchengzi Formation in the Flowerpot Basin are conglomerate, lithic sandstone, and feldspathic litharenite belonging to an alluvial fan and braided river sedimentary system. The main components of the sandstone indicate the provenance rock type.

2) According to the projection points in Dickinson's Qt, F, L and Qm, F, Lt triangular diagrams, the provenance type in this basin is a recycled orogeny belt that reflects the processes from a clastic recycled orogeny such as a collisional orogenic belt to a transitional recycled type.

3) According to the NE-SW ancient flow, it is speculated that the Jurassic Tuchengzi Formation accepted sediment at least from the north, east, and west during the sedimentary period. The three provenances are Archeozoic basal metamorphic rocks and granite in the northern basin and Mesoproterozoic dolomite of the Changchengian and Jixianianian Wumishan Formation at both sides of the basin. 


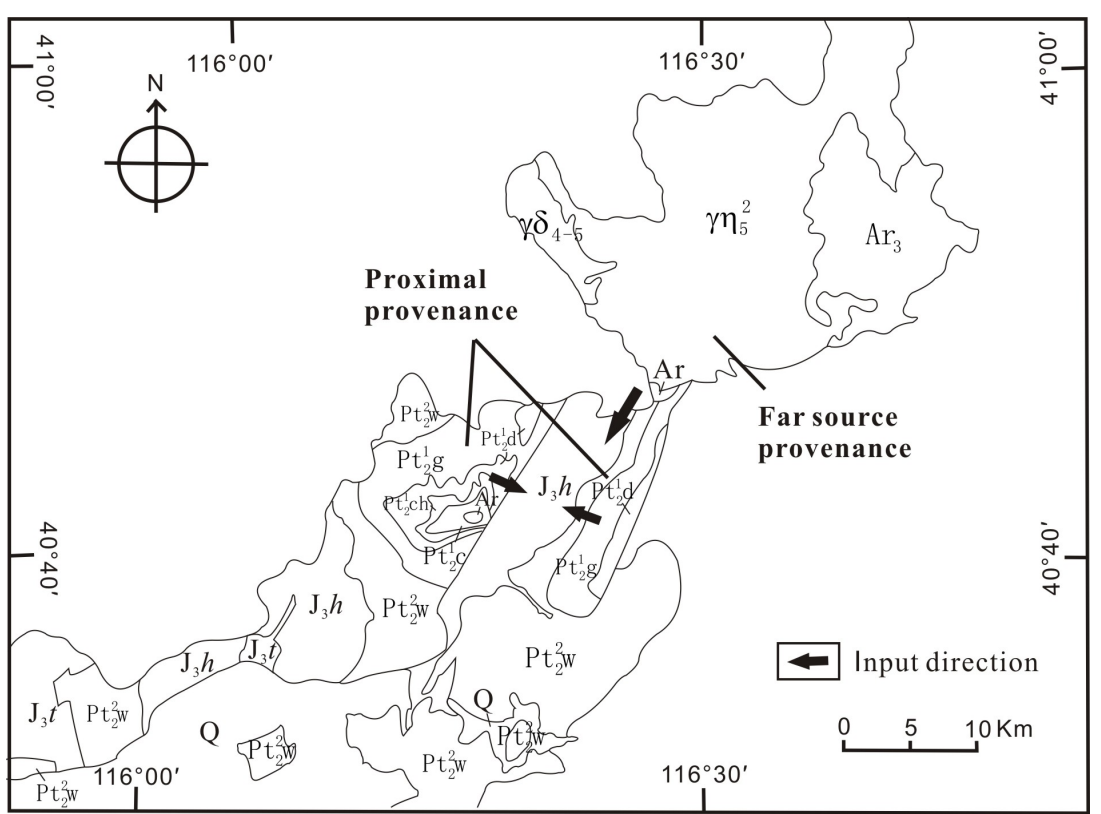

Figure 6. Provenance analysis plane diagram of the Tuchengzi Formation in the Flower Basin.

\section{Acknowledgements}

H.W. was funded by the National Undergraduate Innovation and Entrepreneurship Training Program (No. 201511415074).

\section{References}

[1] Zhang, X., Zhang, J.L. and Qin, L.J. (2007) Petrologic Characteristics and Provenance Analysis of Sandstones in the Kepingtage Formation of Silurian in the Tarim Basin. Journal of Mineralogy and Petrology, 27, 106-115.

[2] Dickinson, W.R. (1976) Plate Tectonic Evolution of Sedimentary Basins. American Association of Petroleum Geologists Continuing Education Course Notes, 1, 1-56.

[3] Ingersoll, R.V., Bullard, T.F. and Ford, R.L. (1984) The Effect of Grain Size on Detrital Modes: A Test of the GazziDickinson Point-Counting Method. Journal of SedimentaryPetrology, 54, 103-116.

[4] Zhang, Y.F., Wei, X.J., Xu, J. and Wang, H. (2012) Continental Sequence Stratigraphy Analysis of "Fossil Wood” Geological Park Section in Yanqing County, Beijing. Earth Science Frontiers, 19, 68-77.

[5] Guo, J., Deng, H.W., Ji, C.H. and Qin, Y.Q. (2011) Sedimentary Characteristic of Braided River of Upper Jurassic Outcrops in North of Beijing. Geoscience, 25, 642-649.

[6] Li, S.W. (2003) Yanqing Silicified Wood National Geological Park. Beijing Archives, 7, 50-51.

[7] Guo, J.F. (2010) Embrace the Hundred-Mile Landscape Corridor to Feel Geological Cultural Heritage One Hundred Million Years before-Note of the Silicified Wood National Geological Park in Yanqing, Beijing. Science \& Culture, 2, 58-59.

[8] Qu, H.J. and Zhang, Y.L. (2005) Characterization of Tuchengzi Formation in Chengde Area and Its Structural Significance. Geotectonicaet Metallogenia, 29, 465-466.

[9] Sun, L.X., Zhao, F.Q., Wang, H.C. and Ji, S.P. (2007) Correlationship of Tuchengzi Formation and Implications of the Basin Tectonic Evolution in the Intracontinental Yanshan Orogenic Belt. Acta Geologica Scinica, 81, 445-454.

[10] He, Z.J., Niu, B.G. and Zhang, X.Y. (2007) Provenance Analysis of the Conglomerate Clastic Compositions from the Late Jurassic Chengde Basin and Its Tectonic Significance. Acta Petrologic Sinica, 23, 655-666.

[11] Zhao, Y. (1990) The Mesozoic Orogenies and Tectonic Evolution of the Yanshan Area. Geological Review, 36, 1-13.

[12] Shao, J.A., Meng, Q.R., Wei, H.Q., Zhang, L.Q. and Wang, P.Y. (2003) Nature and Tectonic Environment of Late Jurassic Volcanic-Sedimentary Basins in Northwestern Hebei Province. Geological Bulletin of China, 22, 751-761.

[13] Liu, S.F., Li, Z. and Zhang, J.F. (2004) Mesozoic Basin Evolution and Tectonic Mechanism in Yanshan. China. Science in China Series D: Earth Sciences, 47, 24-38. http://dx.doi.org/10.1360/04zd0022 
[14] Jiang, Z.X., Zhang, Y.F. and Wang, H.L. (2012) Construction of the Field Practice Teaching Base for the Basis of Sedimentology. Chinese Geological Education, 82, 44-46.

[15] Zhu, X.M. (2008) Sedimentary. Petroleum Industry Press, Beijing, 1-483. (In Chinese)

[16] Zhao, H.G. and Liu, C.Y. (2003) Approaches and Prospects of Provenance Analysis. Acta Sedimentologica Sinica, 21, 409-415.

[17] Liu, L. and Hu, C.Y. (1991) The Provenance Significance of Major Clastic Component in the Sandstone. Lithofacies Paleogeography, 6, 48-53.

[18] Xu, Y.J., Du, Y.S. and Yang, J.H. (2007) Prospects of Sediment Provenance Analysis. Geological Science and Technology Information, 26, 26-32.

[19] Du, Y.L., Li, S.Y., Kong, W.L. and Wang, S. (2010) Sandstone Detrital Composition and Provenance Analysis of the Permian Longtan Formation in Southeastern Anhui Province. Geological Journal of China Universities, 16, 509-516.

[20] Du, H.F., Zhu, Z.J., Jiang, Y.B., Yang, T.N., Liu, Y.X. and Guo, F.S. (2011) Petrologic Characteristics and Provenance Analysis of Sandstones of Gonjo Formation in Nangqen Basin. Acta Petrologica et Mineralogica, 30, 401-408.

[21] Jiang, Z.X. (2010) Sedimentology. Petroleum Industry Press, Beijing, 34-102. (In Chinese)

[22] Xu, H., et al. (2013) Sedimentary Provenance and Basin Evolution of Daqingshan Formation, Houcheng Formation and Tuchengzi Formation in Yinshan-Yanshan Area. Geological Bulletin of China, 32, 502-524.

[23] Wang, Y. and Ji, G.Y. (2014) A Discussion on Petrochemical Feature and Origin of the Volcanic Rocks of Houcheng Formation in Northern Part of Yanqing County, Beijing. Beijing Geology, 16, 16-25.

[24] Bureau of Geology and Mineral Resources of Beijing Municipality (1991) Regional Geology of Beijing Municipality. Geological Publishing House, Beijing, 260-387.

\section{Submit or recommend next manuscript to SCIRP and we will provide best service for you:}

Accepting pre-submission inquiries through Email, Facebook, Linkedin, Twitter, etc A wide selection of journals (inclusive of 9 subjects, more than 200 journals)

Providing a 24-hour high-quality service

User-friendly online submission system

Fair and swift peer-review system

Efficient typesetting and proofreading procedure

Display of the result of downloads and visits, as well as the number of cited articles

Maximum dissemination of your research work

Submit your manuscript at: http://papersubmission.scirp.org/ 